\title{
Adrenal ganglioneuroma: Prognostic factors (Review)
}

\author{
FLORICA SANDRU $^{1,2}$, MIHAI CRISTIAN DUMITRASCU ${ }^{3,4}$, AIDA PETCA $^{3,5}$, MARA CARSOTE $^{6,7}$, \\ RAZVAN-COSMIN PETCA ${ }^{8,9}$, ANA MARIA OPROIU ${ }^{10,11}$ and ADINA GHEMIGIAN ${ }^{6,7}$
}

\begin{abstract}
${ }^{1}$ Department of Dermatology, 'Carol Davila' University of Medicine and Pharmacy, 050474 Bucharest; ${ }^{2}$ Department of Dermatology, 'Elias' Emergency Hospital, 011461 Bucharest; ${ }^{3}$ Department of Obstetrics and Gynecology, 'Carol Davila' University of Medicine and Pharmacy, 050474 Bucharest; ${ }^{4}$ Department of Obstetrics and Gynecology,

University Emergency Hospital of Bucharest, 050098 Bucharest; ${ }^{5}$ Department of Obstetrics and Gynecology, 'Elias' Emergency Hospital, 022461 Bucharest; ${ }^{6}$ Department of Endocrinology, 'Carol Davila' University of Medicine and Pharmacy, 050474 Bucharest; ${ }^{7}$ Department of Endocrinology, 'C. I. Parhon' National Institute of Endocrinology, 011863 Bucharest; ${ }^{8}$ Department of Urology, 'Carol Davila' University of Medicine and Pharmacy, 050474 Bucharest; ${ }^{9}$ Department of Urology, 'Prof. Dr. Theodor Burghele' Clinical Hospital, 061344 Bucharest; ${ }^{10}$ Department of Plastic and Reconstructive Surgery, 'Carol Davila' University of Medicine and Pharmacy, 050474 Bucharest; ${ }^{11}$ Department of

Plastic and Reconstructive Surgery, University Emergency Hospital of Bucharest, 050098 Bucharest, Romania
\end{abstract}

Received July 23, 2021; Accepted August 23, 2021

DOI: 10.3892/etm.2021.10773

\begin{abstract}
Ganglioneuroma, a rare neural crest-derived tumor, exhibits a benign profile in contrast to other neuroblastic tumors (neuroblastoma/ganglioneuroblastoma). Ganglioneuromas can be found anywhere autonomic ganglia are located, mostly abdominal/pelvic sites followed by the adrenal glands (one-third of cases), mediastinum/thorax and cervical area. Affecting especially children more than 10 years of age, Ganglioneuroma is either asymptomatic or may cause local compressive effects; rarely inducing nonspecific abdominal complains or arterial hypertension related to oversecretion of epinephrine/norepinephrine/dopamine. Despite a good prognosis, adrenalectomy is necessary in order to rule out a malignancy. Open procedure represents the standard therapeutic option; alternatively, centers with large laparoscopic pediatric experience and good stratification protocols have
\end{abstract}

Correspondence to: Dr Mihai Cristian Dumitrascu, Department of Obstetrics and Gynecology, 'Carol Davila' University of Medicine and Pharmacy, 8 Street Eroii Sanitari, 050474 Bucharest, Romania E-mail: drdumitrascu@yahoo.com

Abbreviations: ADC, apparent diffusion coefficient; EMT, epithelial-mesenchymal transition; HU, Hounsfield units; I, iodine; IDRF, image defined risk factors; MEN, multiple endocrine neoplasia; mTOR, mechanistic target of rapamycin; MIBG, metaiodobenzylguanidine; NMDAR, anti-N-methyl-D-aspartate receptor; $\mathrm{PKB}$, protein kinase $\mathrm{B}$; ROHHAD(NET) syndrome, rapid obesity with hypoventilation, hypothalamic dysfunction and autonomic dysregulation and neuroendocrine tumor syndrome; $\mathrm{TH}$, tyrosine hydroxylase

Key words: ganglioneuroma, adrenal tumor, adrenal ganglioneuroma, adrenalectomy, neuroblastoma, adrenal medulla, neuroblastic tumor, pediatric surgery, neural crest tumor, adrenal incidentaloma reported successful procedures. High uptake of $\mathrm{I}^{123}$-MIBG is associated with a more severe outcome in cases with increased mitotic index. In neuroblastic tumors, neuron-specific enolase $>33 \mathrm{ng} / \mathrm{ml}$, age at diagnosis > 49 months, and blood vessel invasion indicate a poor prognosis. Concurrent extra-adrenal/adrenal ganglioneuroma is associated with a more severe prognosis; post-surgical complications are more frequent in non-adrenal vs. adrenal ganglioneuroma. Exceptionally, immune-mediated paraneoplastic neurologic syndromes have been reported: anti-N-methyl-D-aspartate receptor encephalitis and opsoclonus-myoclonus-ataxia syndrome. ROHHAD syndrome is the underlying cause in $40-56 \%$ of cases of neuroendocrine tumors including ganglioneuroma; $70 \%$ of tumors are diagnosed within the first 24 months after hypothalamic obesity onset, associated with a severe prognosis due to hypoventilation, sleep apnea, and dysautonomia. Recently, the PKB/AKT/mTOR/S6 pathway was identified as a tumorigenic pathway in pediatric ganglioneuroma, not in neuroblastoma; mTOR inhibitors are a potential option for pre-operatory tumor shrinkage. Pediatric adrenal ganglioneuroma has a good prognosis if adequately treated; its recognition requires adrenalectomy. Further development of specific biomarkers is needed. In the present article, we aimed to introduce a review of the literature involving adrenal ganglioneuroma based on a practical, multidisciplinary perspective of prognostic factors.

\section{Contents}

1. Introduction

2. Aim of the review

3. Presentation of an adrenal ganglioneuroma

4. Syndromic circumstances

5. Extra-adrenal ganglioneuroma

6. Ganglioneuroma as adrenal incidentaloma 
7. Pediatric adrenalectomy

8. Advanced biomarkers

9. Future considerations

10. Conclusions

\section{Introduction}

Adrenal tumors in children are associated with a broad range of presentations most of which have an aggressive profile such as neuroblastoma, poorly differentiated pheocromocytoma and adrenocortical carcinoma (1). Mostly benign features are found in pure cystic lesions (2). Neuroblastoma, ganglioneuroma and neuroblastoma-ganglioneuroma (also called ganglioneuroblastoma) originate from neural crest progenitor cells/sympathogonia (including adrenal medulla), so called neuroblastic tumors, together representing the most frequent extracranial solid pediatric tumors. At the end of the aggressive spectrum, there is neuroblastoma, while at the other end exhibiting generally considered benign features there is ganglioneuroma (3). Adrenal medulla is also the origin of pheochromocytomas with different grades of differentiation and associated malignant potential and also composite pheochromocytoma, a distinct rare entity $(4,5)$.

Ganglioneuroma, a benign tumor of neuroblastic type, originates from the autonomous sympathetic nervous system, either central or peripheral; thus, the sites can be anywhere in relationship to the presence of autonomic ganglia such as the adrenals, retroperitoneum, mediastinum/thorax, and cervical area $(4,5)$. Ganglioneuroma is considered to be a tumor with the least aggressive profile among all neuroblastic tumors since it exclusively has mature cells; it is also the rarest tumor of this category (6). One-third of ganglioneuromas are located at the adrenal level (7). Ganglioneuromas are typically found in patients over 10 years of age; they are asymptomatic or they are associated with compressive local effects (7).

Surgery is required when a clear identification of the ganglioneuroma cannot be done in the absence of a post-operative histological report or when the tumor is large or is associated with local compressive symptoms (8). Overall, a very good prognosis is described (8).

The largest meta-analysis concerning ganglioneuroma, regardless of age, was published in 2021 (including published cases on PubMed between 1995 and 2018); they found 364 cases; $65.7 \%$ were adults; female predominance (62\%); incidental detection in $24.5 \%$ of all cases; and most frequent sites were abdomen/pelvis (66.2\%) followed by adrenal ganglioneuroma (32.1\%). Post-operative complications were the rarest after adrenalectomy (1\%) when compared to head, neck and thorax location; and no recurrence was reported confirming the benign behavior independent of age (9).

\section{Aim of the review}

We aimed to introduce a review of the literature involving adrenal ganglioneuroma based on practical, multidisciplinary perspective of prognostic factors.

This is a narrative, PubMed-based review of literature focused on practical points regarding ganglioneuroma and prognostic factors. We cited 73 papers published within the last 10 years (published between 2021 and 2012). The researched key words in different combinations included 'ganglioneuroma', 'neuroblastoma', 'pediatric', 'children', 'adrenal', 'outcome', 'prognostic'. The criteria of inclusion were practical and clinical relevance. We only included full length, original, English language published papers with various degrees of statistical power due to the rarity of the tumor.

\section{Presentation of an adrenal ganglioneuroma}

Adrenal ganglioneuromas usually lack specific signs and symptoms. It has a negative endocrine profile, but it has the potential to mimic other adrenal cancers when it comes to imaging findings; thus, the importance of its removal in order to obtain post-operative pathological identification (10). Non-specific abdominal distention and complaints which are not directly regarded as a marker of poor prognosis have been described; oversecretion of epinephrine/norepinephrine/dopamine is exceptional; also high blood pressure is extremely rarely associated $(11,12)$. Exceptionally, immune-mediated paraneoplasic neurologic syndromes have been reported including: NMDAR (anti-N-methyl-D-aspartate receptor) encephalitis and opsoclonus-myoclonus-ataxia syndrome (13).

At imaging evaluation, a cutoff of $3 \mathrm{~cm}$ has been suggested between large and small adrenal ganglioneuroma with respect to different behaviors (14). High uptake of $\mathrm{I}^{123}$-MIBG (metaiodobenzylguanidine) is associated with a poor prognosis as seen in neuroblastomas and ganglioneuromas with increased mitotic index; while some tumors, regardless of whether they are ganglioneuromas or neuroblastomas, are $\mathrm{I}^{123}$-MIBG-negative. In addition, false-positive results are due to focal nodular hyperplasia $(15,16)$.

One study on pediatric and adult ganglioneuromas showed that 27 out of 53 were adrenal tumors. Overall, the age interval was between 1.7 years and 64 years (mean of 31 years), the median tumor size was $8 \mathrm{~cm}$. A negative hormonal profile was confirmed and two-thirds of the adrenal ganglioneuromas were incidentally detected (17). Another large study on 345 subjects with neuroblastic tumors $(24.6 \%$ were ganglioneuromas and $75.4 \%$ were neuroblastomas) demonstrated that the most important factors for malignancy prediction were: A pre-operatory level of serum neuron-specific enolase higher than $33 \mathrm{ng} / \mathrm{ml}$, an age at diagnosis younger than 49 months, and blood vessel invasion (18).

\section{Syndromic circumstances}

Rapid Obesity with Hypoventilation, Hypothalamic dysfunction and Autonomic Dysregulation and NEuroendocrine Tumor [ROHHAD(NET)] syndrome or ROHHAD syndrome is an exceptional rare syndrome, first described in 2007, with a high risk of fatal outcome in children aged between 2 and 4 years $(19,20)$. It consists of hypothalamic obesity similar with monogenetic obesity syndromes, psychiatric conditions, hypoventilation complicated with pulmonary hypertension, sleep apnea, and dysautonomia following obesity within a few years $(21,22)$. In addition, tumors originating from the neural crest including 
ganglioneuroma have been reported, indicating that $40-56 \%$ of patients develop a neuroendocrine tumor including a ganglioneuroma and $70 \%$ of them are detected within the first 24 months after the onset of obesity $(23,24)$. No specific marker is an adequate prognostic predictor under these severe circumstances and the genetic background is still unknown (25). The initial evidence of ROHHAD syndrome is rapidly progressing obesity in a previous healthy child (24).

Limited data concerning the association between pediatric ganglioneuroma and papillary thyroid cancer or multiple endocrine neoplasia (MEN) type 2A syndrome are available to date (26). In addition, a report of Turner syndrome for a patient with ganglioneuroma is probably incidental (27). One girl with constitutional 11q interstitial deletion syndrome was reported with concurrent adrenal neuroblastoma and prevertebral ganglioneuroma (28). A case of a 13-year female with adrenal ganglioneuroma and a syndrome of hereditary spherocytosis was previously published, probably also an accidental association (29). Neurogenic tumors of different locations include a large range of Schwann cell originating tumors with or without neuroblastic differentiation, and ganglioneuromas need to be differentiated from schwannomas or neurofibromas, also associated with classical features of neurofibromatosis type 1 syndrome $(30,31)$. A few cases of gastrointestinal ganglioneuromatosis associated with the presence of neurofibromatosis type 1 , MEN type $2 \mathrm{~B}$ syndrome and Cowden syndrome (PTEN gene mutation) have been reported (32).

\section{Extra-adrenal ganglioneuroma}

Extra-adrenal ganglioneuroma may be present in a patient as a single neuroblastic tumor or, rarely, synchronously in two different locations; concurrent adrenal and non-adrenal ganglioneuromas are associated with a more severe prognosis than a single adrenal mass (33). Cervical ganglioneuromas originate from Schwann cells of cervical sympathetic ganglia or are related to vagus/hypoglossal nerves; they need to be differentiated from head and neck tumors of soft tissue (34). The confirmation comes after tumor removal and consecutive histological report, as seen in adrenal ganglioneuroma (35). Excision is necessary despite the slow rate of growth, because of compressive local symptoms such as Claude-Bernard-Horner syndrome (ptosis, myosis, facial anhidrosis and flushing) (36).

The prognosis is good but surgery is needed first because of the many alternative diagnoses concerning cervical masses (carotid body tumor, ectopic parathyroid, ectopic thyroid) that cannot be identified without adequate pathological examination and second, due to tumor-related vagus/hypoglossal nerve damage or Horner syndrome (which otherwise has been described also as a complication of neoplasia removal) risk which may aggravate the overall clinical picture and associated permanent damage $(37,38)$. Resection of head and neck, pelvis or mediastinal ganglioneuromas has a higher risk of post-operative complications when compared to adrenal ganglioneuromas while the presentation depends on the local anatomy (39).

\section{Ganglioneuroma as adrenal incidentaloma}

The imaging findings of an adrenal ganglioneuroma as an incidentaloma is not rare, resulting less from tumor-related complications, but more from non-tumor associated elements that require an abdominal ultrasound or an abdominal computed tomography/magnetic resonance imaging $(40,41)$. The examination of adrenal glands represents a standard routine procedure during abdominal ultrasound both in children and adults (42). The detection of an asymptomatic adrenal ganglioneuroma may be conducted later during adult life, but generally adult tumors that are diagnosed as a true adrenal incidentaloma (non-functioning tumor with a low rate of growth, without suspected malignancy) are not referred for surgery by endocrinologist since the incidence of an adrenal incidentaloma is age dependent and they generally involve a low index of suspected aggressive behavior $(43,44)$.

A study on 1,784 patients admitted between 2002 and 2015 for adrenalectomy showed that for $1.9 \%$ of the patients who were confirmed with ganglioneuroma (mean age of 33.4 years) that pre-contrast Hounsfield units (HU) at pre-operative computed tomography and higher post-contrast phase attenuation are suggestive for a ganglioneuroma in association with well-shaped margins (3). Nevertheless, an adrenal incidental finding in the pediatric population requires a complete endocrine panel of investigation and subsequently the patient is referred for adrenalectomy as there is no 'true' incidentaloma (a tumor underlying a cortical adenoma) at this segment of age (44).

\section{Pediatric adrenalectomy}

Subtotal adrenal resection is performed by some centers; otherwise, it is not a standard of approach (3). A study of 808 patients with neuroblastic tumors who underwent an adrenalectomy between 2000 and 2010 identified 162 cases of ganglioneuroma (20\%); $70 \%$ of the ganglioneuromas had complete removal, the others had a subtotal resection that seemed safe for a median follow-up of 44 months after surgery (3). Since the degree of tumor differentiation cannot be exactly known before adrenalectomy (meaning that the tumor may be a neuroblastoma or a ganglioneuroblastoma), complete excision is encouraged (45).

A retrospective study in 2020 on 50 subjects $(6 / 50$ were ganglioneuromas) with a mean age of 4.8 years who underwent an adrenalectomy between 2007 and 2017 showed that the decision of surgery (laparotomy, which was more frequently used vs. laparoscopy) was based on tumor size at imaging assessment and image defined risk factors (IDRFs) (46). In one study from the Mayo Clinic focusing on pediatric surgery between 1993 and 2012, surgery performed for different endocrine conditions found in 241 cases aged less than 19 years, one case of ganglioneuroma (47). The adrenalectomies performed for various tumors were either laparoscopic or open (47).

Minimal access adrenal surgery (MAAS) is the standard for pediatric adrenal surgery in centers with large experience in laparoscopy (48). A multi-centric, retrospective European study between 2002 and 2013 included 68 children with a mean age of 5.2 years (3/68 were ganglioneuromas); $92.6 \%$ of the studied population had a trans-peritoneal access and $7.4 \%$ had a retro-peritoneal access while conversion to open approach was not needed (49). Laparoscopic approach represents a good alternative to standard open approach 
in children, but it requires a specific pediatric experience independent of tumor pre-operative features (50). Anterior vs. retroperitoneal approach is indicated in large tumors and in subjects with smaller retroperitoneal space (51). Currently, the open technique is recommended, but minimally invasive surgery may be used based on the surgeon's experience and pre-operative risk stratification assessments (52).

\section{Advanced biomarkers}

Recently, the protein kinase B (PKB)/AKT system was detected as a tumorigenic pathway in pediatric ganglioneuroma and mechanistic target of rapamycin (mTOR) inhibition may help (53). The AKT/mTOR/S6 mechanism is related to ganglioneuroma, not neuroblastoma (54). Potential use of mTOR inhibitors is yet to be determined, possibly as pre-operative medication to reduce the tumor size in order to facilitate complete neoplasia surgical removal $(53,54)$. Moreover, transcription factor insulinoma-associated protein 1 (INSM1) was found to be positive in aggressive neuroblastomas and ganglioneuromas, and its role as a prognostic factor is yet to be determined (55).

Other poor prognostic biomarkers are limited to the aggressive profile of neuroblastomas, not ganglioneuroma. These include epithelial-mesenchymal transition (EMT)-related pre-mRNA processing factor 19 (Prp19) (56). The Bcl-2 gene, related to programmed cell death, encodes an oncoprotein that has been suggested to help the differentiation between ganglioneuroma/neuroblastoma based on Bcl-2 immunostaining, but currently it is not considered a relevant prognostic marker (57). However, when it comes to neuroblastoma, an aggressive neural crest-derived tumor with an overall survival rate of less than $50 \%$, several abnormal signal transduction pathways have been identified including: TP53, ALT, ADAM22, ATRX, GAL, RAS/MAPK, KLHL13, $\beta 3$-adrenergic receptor, and TWIST1 $(58,59)$. HuC/D, an RNA binding protein, may be a marker of neuroblastic cells but not a distinctive factor between neuroblastoma/ganglioneuroma (60). Tyrosine hydroxylase (TH) has been used as a sympathoadrenal marker for tumors originating from the neural crest, and currently Phox2B has been confirmed to be a better marker especially for undifferentiated neuroblastoma and cases with negative TH expression (61).

Another novel imaging biomarker is the use of the apparent diffusion coefficient (ADC) derived from magnetic resonance quantitative analysis in cases with neuroblastic tumors to improve the assessment in the absence of surgery or pre-operatively (62).

\section{Future considerations}

Several aspects are still an open subject concerning the field of ganglioneuroma. One is related to the complex panel of risk factors related to tumor appearance. Whether or not maternal and intra-fetal exposure to different endocrine disruptors may be a contributor to early tumorigenesis is yet unknown (63). There is also a need for developing scoring systems for adequate management which is a relatively difficult issue since the level of statistical evidence is heterogeneous due to the rarity of the tumor (64). Another aspect is the fact that, except for symptomatic or hormonally active cases and situations where imaging follow-up shows a certain rate of tumor growth, tumor removal may not seem imperious; however, until complete histological evaluation and profiling of the lesion are conducted, a malignancy cannot be otherwise excluded. Thus, the importance of, not only a positive diagnosis, but also of a differential diagnosis as provided after surgery in adrenal as well as non-adrenal ganglioneuroma cases, must be stressed (65).

In regards to pediatric adrenalectomy, the skill and experience of the surgeon represent the key factors by which to select the procedure. Thus, there are no clear-cut general recommendations (66-68). In contrast to this, the same procedure in adults has an excellent outcome using the laparoscopic approach which is preferred in most situations, except for very large, potentially malign, invasive adrenal masses (66-68). It is well known that the term 'adrenal incidentaloma' which is mostly associated with an adrenocortical adenoma in adults, is controversial in children as tumors such as ganglioneuroma may embrace this scenario; however, tumor removal seems essential in this situation, in contrast to adult adrenal incientaloma, which requires in most cases just a periodic endocrine assessment and serial imaging follow-up (69-71).

\section{Conclusions}

Pediatric adrenal ganglioneuroma represents a tumor with a good prognosis if adequately treated. However, its recognition requires adrenalectomy which is associated with a good outcome when compared to other surgical procedures for non-adrenal ganglioneuromas. A syndromic context makes the overall outcome more severe. Further development of specific biomarkers is needed.

\section{Acknowledgements}

Not applicable.

\section{Funding}

No funding was received.

\section{Availability of data and materials}

Not applicable.

\section{Authors' contributions}

FS drafted the manuscript and critically revised the final form. MCD researched the literature and is the corresponding author. AP researched the literature, and MC drafted the manuscript and revised the content. RCP revised the final form in light of the literature data and wrote the conclusions. AMO researched the literature, and AG approved the final form after reviewing all of the literature findings. All authors read and approved the final manuscript for publication.

\section{Ethics approval and consent to participate}

Not applicable. 


\section{Patient consent for publication}

Not applicable.

\section{Competing interests}

The authors declare that they have no competing interests.

\section{References}

1. Jarzembowski JA: New prognostic indicators in pediatric adrenal tumors: Neuroblastoma and adrenal cortical tumors, can we predict when these will behave badly? Surg Pathol Clin 13: 625-641, 2020.

2. Carsote M, Ghemigian A, Terzea D, Gheorghisan-Galateanu AA and Valea A: Cystic adrenal lesions: Focus on pediatric population (a review). Clujul Med 90: 5-12, 2017.

3. Lee JH, Chai YJ, Kim TH, Choi JY, Lee KE, Kim HY, Yoon YS and Kim HH: Clinicopathological features of ganglioneuroma originating from the adrenal glands. World J Surg 40: 2970-2975, 2016.

4. Dhanasekar K, Visakan V, Tahir F and Balasubramanian SP: Composite phaeochromocytomas-a systematic review of published literature. Langenbecks Arch Surg: Mar 2, 2021 (Epub ahead of print).

5. Lam AK: Update on adrenal tumours in 2017 World Health Organization (WHO) of endocrine tumours. Endocr Pathol 28: 213-227, 2017

6. Mylonas KS, Schizas D and Economopoulos KP: Adrenal ganglioneuroma: What you need to know? World J Clin Cases 5: 373-377, 2017

7. Burroughs MA Jr, Urits I, Viswanath O, Kaye AD and Hasoon J: Adrenal ganglioneuroma: A rare tumor of the autonomic nervous system. Cureus 12: e12398, 2020.

8. Spinelli C, Rossi L, Barbetta A, Ugolini C and Strambi S: Incidental ganglioneuromas: A presentation of 14 surgical cases and literature review. J Endocrinol Invest 38: 547-554, 2015.

9. Fliedner SMJ, Winkelmann PER, Wesley R, Vonthein R and Lehnert H: Ganglioneuromas across age groups: Systematic review of individual patient data. Clin Endocrinol (Oxf) 94 12-23, 2021.

10. Sargar KM, Khanna G and Hulett Bowling R: Imaging of nonmalignant adrenal lesions in children. Radiographics 37 : 1648-1664, 2017

11. Burns AJ, Sullivan KM, Koh EK, Tretiakova MS and Zern NK Dopamine secreting adrenal tumor-ganglioneuroma rather than pheochromocytoma: Case report. Gland Surg 9: 2204-2210, 2020.

12. Erem C, Fidan M, Civan N, Cobanoglu U, Kangul F, Nuhoglu I and Alhan E: Hormone-secreting large adrenal ganglioneuroma in an adult patient: A case report and review of literature. Blood Press 23: 64-69, 2014.

13. Escudero-Fernandez JM, Garcia-Carpintero AS Delgado-Alvarez I, Castellote-Alonso A and Vázquez-Mendez EJ Brain paraneoplastic syndromes in a patient with mediastinal ganglioneuroma. Radiol Case Rep 15: 2059-2062, 2020.

14. Shao M, Zhang W, Niu Z, Chen S, Jia Y, An Y, Zhu F and Wang J: Computed tomography characteristics of adrenal ganglioneuroma: A retrospective analysis of 30 pathologically-confirmed cases. J Int Med Res 48: 300060520945510, 2020.

15. Kulatunge CR and Son H: False-positive 123I-MIBG scintigraphy due to multiple focal nodular hyperplasia. Clin Nucl Med 38: 976-978, 2013.

16. Fendler WP, Melzer HI, Walz C, von Schweinitz D, Coppenrath E, Schmid I, Bartenstein P and Pfluger T: High ${ }^{123}$ I-MIBG uptake in neuroblastic tumours indicates unfavourable histopathology. Eur J Nucl Med Mol Imaging 40: 1701-1710, 2013.

17. Shawa H, Elsayes KM, Javadi S, Morani A, Williams MD, Lee JE, Waguespack SG, Busaidy NL, Vassilopoulou-Sellin R, Jimenez $\mathrm{C}$ and Habra MA: Adrenal ganglioneuroma: Features and outcomes of 27 cases at a referral cancer centre. Clin Endocrinol (Oxf) 80: 342-347, 2014

18. Yang S, Cai S, Ma X, Zeng Q, Qin H, Han W, Peng X and Wang H: Discrimination of histopathologic types of childhood peripheral neuroblastic tumors based on clinical and biological factors. Sci Rep 8: 10924, 2018.
19. Şiraz ÜG, Ökdemir D, Direk G, Akın L, Hatipoğlu N, Kendirci M and Kurtoğlu S: ROHHAD syndrome, a rare cause of hypothalamic obesity: Report of two cases. J Clin Res Pediatr Endocrinol 10: 382-386, 2018.

20. Ibáñez-Micó S, Marcos Oltra AM, de Murcia Lemauviel S, Ruiz Pruneda R, Martínez Ferrández C and Domingo Jiménez R: Rapid-onset obesity with hypothalamic dysregulation, hypoventilation, and autonomic dysregulation (ROHHAD syndrome): A case report and literature review. Neurologia 32: 616-622, 2017 (In English, Spanish).

21. Özcan G, Özsu E, Siklar Z and Çobanoğlu N: A rare cause of sleep-disordered breathing: ROHHAD syndrome. Front Pediatr 8: 573227, 2020.

22. Stowe RC and Afolabi-Brown O: Pulmonary hypertension and chronic hypoventilation in ROHHAD syndrome treated with average-volume assured pressure support. Pediatr Investig 3: 253-256, 2019.

23. Abaci A, Catli G, Bayram E, Koroglu T, Olgun HN, Mutafoglu K, Hiz AS, Cakmakci $\mathrm{H}$ and Bober E: A case of rapid-onset obesity with hypothalamic dysfunction, hypoventilation, autonomic dysregulation, and neural crest tumor: ROHHADNET syndrome. Endocr Pract 19: e12-e16, 2013.

24. Harvengt J, Gernay C, Mastouri M, Farhat N, Lebrethon MC, Seghaye MC and Bours V: ROHHAD(NET) syndrome: Systematic review of the clinical timeline and recommendations for diagnosis and prognosis. J Clin Endocrinol Metab 105: dgaa247, 2020.

25. Barclay SF, Rand CM, Borch LA, Nguyen L, Gray PA, Gibson WT, Wilson RJ, Gordon PM, Aung Z, Berry-Kravis EM, et al: Rapid-onset obesity with hypothalamic dysfunction, hypoventilation, and autonomic dysregulation (ROHHAD): Exome sequencing of trios, monozygotic twins and tumours. Orphanet J Rare Dis 10: 103, 2015.

26. Fang CW, Wang JS, Wu TT and Lin JT: Occurrence of paratesticular ganglioneuroma 18 years after concurrent adrenal ganglioneuroma and papillary thyroid carcinoma-a case report. BMC Cancer 19: 1265, 2019.

27. Wikiera B, Nocoń-Bohusz J, Godziński J and Noczyńska A: Ganglioneuroma in a patient with turner syndrome. Pediatr Endocrinol Diabetes Metab 19: 115-118, 2013.

28. Shiohama T, Fujii K, Hino M, Shimizu K, Ohashi H, Kambe M, Nakatani Y, Mitsunaga T, Yoshida H, Ochiai H and Shimojo N: Coexistence of neuroblastoma and ganglioneuroma in a girl with a hemizygous deletion of chromosome 11q14.1-23.3. Am J Med Genet A 170A: 492-497, 2016.

29. Demir HA, Ozdel S, Kaçar A, Senel E, Emir S and Tunç B: Ganglioneuroma in a child with hereditary spherocytosis. Turk J Pediatr 54: 187-190, 2012.

30. Rodriguez EF, Jones R, Miller D and Rodriguez FJ: Neurogenic tumors of the mediastinum. Semin Diagn Pathol 37: 179-186, 2020.

31. Sandru F, Carsote M, Valea A, Albu SE, Petca RC and Dumitrascu MC: Somatostatinoma: Beyond neurofibromatosis type 1 (review). Exp Ther Med 20: 3383-3388, 2020.

32. Williams AJ, Doherty ES, Hart MH and GriderDJ: Diffuse gastric ganglioneuromatosis: Novel presentation of PTEN hamartoma syndrome-case report and review of gastric ganglioneuromatous proliferations and a novel PTEN gene mutation. Case Rep Med 2018: 4319818, 2018

33. AlGhamdi MH, AlAyed A, AlShabyli NA, AlGhamdi NH and Al Rasheed M: Concurrent adrenal and extra-adrenal ganglioneuromas: A case report. Am J Case Rep 20: 1817-1820, 2019.

34. Xu T, Zhu W and Wang P: Cervical ganglioneuroma: A case report and review of the literature. Medicine (Baltimore) 98: e15203, 2019.

35. Jackson JR, Tran HC, Stein JE, Shimada H, Patel AM, Marachelian A and Kim ES: The clinical management and outcomes of cervical neuroblastic tumors. J Surg Res 204: 109-113, 2016.

36. Kiflu W and Negussie T: Ganglioneuroma of the neck: A case report. Ethiop Med J 55: 69-71, 2017.

37. Garzorz N, Diercks GR, Lin HW, Faquin WC, Romo LV and Hartnick CJ: A case of pediatric parapharyngeal space ganglioneuroma. Ear Nose Throat J 95: E16-E20, 2016.

38. Bakshi J, Mohammed AW, Lele S and Nada R: Ganglioneuromas involving the hypoglossal nerve and the vagus nerve in a child: Surgical difficulties. Ear Nose Throat J 95: E22-E24, 2016.

39. Wu Z, Zeng Q, Zhang X, Tu S and Zhang F: Ganglioneuroma in unusual sites: Clinical, radiologic and pathological features. Int J Clin Exp Pathol 11: 4862-4866, 2018. 
40. Zvizdic Z,Haxhija E, Chikha A, Milisic E, Jonuzi A and Vranic S Laparoscopic extirpation of adrenal gland ganglioneuroma incidentally diagnosed during evaluation for patchy alopecia areata in an adolescent boy. Med Princ Pract 28: 485-489, 2019.

41. Kanthan R, Senger JL and Kanthan S: Three uncommon adrenal incidentalomas: A 13-year surgical pathology review. World J Surg Oncol 10: 64, 2012.

42. Słapa RZ, Jakubowski WS, Dobruch-Sobczak K and Kasperlik-Załuska AA: Standards of ultrasound imaging of the adrenal glands. J Ultrason 15: 377-387, 2015.

43. Ichijo $T$, Ueshiba $H$, Nawata $H$ and Yanase T: A nationwide survey of adrenal incidentalomas in Japan: The first report of clinical and epidemiological features. Endocr J 67: 141-152, 2020.

44. Fassnacht M, Arlt W, Bancos I, Dralle H, Newell-Price J, Sahdev A, Tabarin A, Terzolo M, Tsagarakis S and Dekkers OM: Management of adrenal incidentalomas: European society of endocrinology clinical practice guideline in collaboration with the European network for the study of adrenal tumors. Eur J Endocrinol 175: G1-G34, 2016.

45. Decarolis B, Simon T, Krug B, Leuschner I, Vokuhl C, Kaatsch P, von Schweinitz D, Klingebiel T, Mueller I, Schweigerer L, et al: Treatment and outcome of ganglioneuroma and ganglioneuroblastoma intermixed. BMC Cancer 16: 542, 2016.

46. He WG, Yan Y, Tang W, Cai R and Ren G: Clinical and biological features of neuroblastic tumors: A comparison of neuroblastoma and ganglioneuroblastoma. Oncotarget 8: 37730-37739, 2017.

47. Kundel A, Thompson GB, Richards ML, Qiu LX, Cai Y, Schwenk FW, Lteif AN, Pittock ST, Kumar S, Tebben PJ, et al: Pediatric endocrine surgery: A 20-year experience at the mayo clinic. J Clin Endocrinol Metab 99: 399-406, 2014.

48. Emre Ş, Özcan R, Bakır AC, Kuruğoğlu S, Çomunoğlu N, Şen HS, Celkan T and Tekant GT: Adrenal masses in children: Imaging, surgical treatment and outcome. Asian J Surg 43: 207-212, 2020.

49. Fascetti-Leon F, Scotton G, Pio L, Beltrà R, Caione P, Esposito C, Mattioli G, Saxena AK, Sarnacki S and Gamba P: Minimally invasive resection of adrenal masses in infants and children: Results of a European multi-center survey. Surg Endosc 31: 4505-4512, 2017.

50. Rodríguez Iglesias P, Gómez-Chacón Villalba J, Rodríguez Caraballo L, Ortolá Fortes P, Cortés Sáez J, Marco Macián A and Vila Carbó JJ: Laparoscopic adrenalectomy: Advantages of the minimally invasive approach. Cir Pediatr 29: 162-165, 2016 (In Spanish).

51. Eassa W, El-Sherbiny M, Jednak R and Capolicchio JP: The anterior approach to retroperitoneoscopic adrenalectomy in children: Technique. J Pediatr Urol 8: 35-39, 2012.

52. ElHaddad A, Castellani C, Sorantin E, Benesch M, Kampelmühler E, Singer G and Till H: Minimally invasive surgery for pediatric adrenal masses-report on four cases. European J Pediatr Surg Rep 7: e75-e78, 2019.

53. Tao T, Shi H, Durbin AD and Look AT: Targeting ganglioneuromas with mTOR inhibitors. Mol Cell Oncol 8: $1856621,2021$.

54. Tao T, Shi H, Wang M,Perez-Atayde AR,London WB, GutierrezA, Lemos B, Durbin AD and Look AT: Ganglioneuromas are driven by activated AKT and can be therapeutically targeted with mTOR inhibitors. J Exp Med 217: e20191871, 2020.

55. Wang H, Krishnan C and Charville GW: INSM1 expression in peripheral neuroblastic tumors and other embryonal neoplasms. Pediatr Dev Pathol 22: 440-448, 2019

56. Cai Y, Chen K, Cheng C, Xu Y, Cheng Q, Xu G, Wu Y and Wu Z: Prp19 is an independent prognostic marker and promotes neuroblastoma metastasis by regulating the hippo-YAP signaling pathway. Front Oncol 10: 575366, 2020.
57. Fetahu IS and Taschner-Mandl S: Neuroblastoma and the epigenome. Cancer Metastasis Rev 40: 173-189, 2021.

58. Liu Z, Grant CN, Sun L, Miller BA, Spiegelman VS and Wang HG: Expression patterns of immune genes reveal heterogeneous subtypes of high-risk neuroblastoma. Cancers (Basel) 12: 1739, 2020.

59. Deng J, Jiang P, Yang T, Huang M, Qi W, Zhou T, Yang Z, Zou Y, Gao $\mathrm{G}$ and Yang $\mathrm{X}$ : Targeting $\beta 3$-adrenergic receptor signaling inhibits neuroblastoma cell growth via suppressing the mTOR pathway. Biochem Biophys Res Commun 514: 295-300, 2019.

60. Takemoto J, Kuda M, Kohashi K, Yamada Y, Koga Y, Kinoshita I, Souzaki R, Taguchi T and Oda Y: HuC/D expression in small round cell tumors and neuroendocrine tumors: A useful tool for distinguishing neuroblastoma from childhood small round cell tumors. Hum Pathol 85: 162-167, 2019.

61. Warren M, Matsuno R, Tran $\mathrm{H}$ and Shimada H: Utility of Phox $2 b$ immunohistochemical stain in neural crest tumours and non-neural crest tumours in paediatric patients. Histopathology 72: 685-696, 2018.

62. Cerdá Alberich L, Sangüesa Nebot C, Alberich-Bayarri A, Carot Sierra JM, Martínez de Las Heras B, Veiga Canuto D, Cañete A and Martí-Bonmatí L: A confidence habitats methodology in MR quantitative diffusion for the classification of neuroblastic tumors. Cancers (Basel) 12: 3858, 2020.

63. Ahmed KEM, Frøysa HG, Karlsen OA, Blaser N, Zimmer KE, Berntsen HF, Verhaegen S, Ropstad E, Kellmann R and Goksøyr A: Effects of defined mixtures of POPs and endocrine disruptors on the steroid metabolome of the human H295R adrenocortical cell line. Chemosphere 218: 328-339, 2019.

64. Picard C, Orbach D, Carton M, Brugieres L, Renaudin K, Aubert S, Berrebi D, Galmiche L, Dujardin F, Leblond P, et al: Revisiting the role of the pathological grading in pediatric adrenal cortical tumors: Results from a national cohort study with pathological review. Mod Pathol 32: 546-559, 2019.

65. Mardi K, Thakur RC and Biswas B: Ganglioneuroma arising from the L5 nerve root: A rare case report. Asian J Neurosurg 10: 232-233, 2015.

66. Paduraru DN, Nica A, Carsote M and Valea A: Adrenalectomy for Cushing's syndrome: Do's and don'ts. J Med Life 9: 334-341, 2016.

67. Valea A, Ghervan C, Carsote M, Albu SE and Georgescu CE: Different surgical options in Cushing's disease. J Surg Sci 3: 39-43, 2016.

68. Nica AE, Carsote M, Paduraru DN and Valea A: Bilateral adrenalectomy and Nelson's syndrome. Arch Balk Med Union 51: 282-285, 2016

69. Carsote M, Valea A, Dumitru N, Terzea D, Petrova E, Albu S, Buruiana $A$ and Ghemigian A: Metastases in daily endocrine practice. Arch Balk Med Union 51: 478-482, 2016.

70. Araujo-Castro M, Iturregui Guevara M, Calatayud Gutiérrez M, Parra Ramírez P, Gracia Gimeno P, Hanzu FA and Lamas Oliveira C: Practical guide on the initial evaluation, follow-up, and treatment of adrenal incidentalomas adrenal diseases group of the Spanish society of endocrinology and nutrition. Endocrinol Diabetes Nutr (Engl Ed) 67: 408-419, 2020 (In English, Spanish).

71. Maas M, Nassiri N, Bhanvadia S, Carmichael JD, Duddalwar V and Daneshmand S: Discrepancies in the recommended management of adrenal incidentalomas by various guidelines. J Urol 205: 52-59, 2021. 